Res., Soc. Dev. 2019; 8(3):e4583838

ISSN 2525-3409 | DOI: http://dx.doi.org/10.33448/rsd-v8i3.838

\title{
Perfil dos professores de ciências da Rede Municipal de Ensino de Barra Mansa
}

Profile of science teachers of the Municipal Teaching Network of Barra Mansa

Perfil de los profesores de ciencias de la Red Municipal de Enseñanza de Barra Mansa

\section{Lucas Peres Guimarães}

ORCID: https://orcid.org/0000-0003-1648-2019

Prefeitura Municipal de Barra Mansa, Brasil

E-mail: lucaspegui@hotmail.com

Valéria da Silva Lima

Prefeitura Municipal de Barra Mansa, Brasil

E-mail: valeriaslima8910@yahoo.com.br

Maylta Brandão dos Anjos

ORCID: https://orcid.org/0000-0001-6272-5056

Instituto Federal de Educação, Ciência e Tecnologia do Rio de Janeiro, Brasil

E-mail: maylta@yahoo.com.br

Recebido: 12/12/2018 | Revisado: 19/12/2018 | Aceito: 21/12/2018 | Publicado: 28/12/2018

\section{Resumo}

Este artigo apresenta o perfil dos professores de Ciências do Ensino Fundamental da Rede Municipal de Ensino de Barra Mansa (SME- BM). Para traçar esse perfil, foi desenvolvido um estudo de caráter qualitativo com base nos dados coletados em uma formação continuada em 2017. O objetivo da pesquisa foi verificar as dificuldades e necessidades dos professores de sala de aula a fim de buscar possibilidades de formação continuada que correspondesse a realidade vivenciada pelos docentes em sala de aula. Os resultados da pesquisa contribuem para ampliar a compreensão sobre os desafios dos professores de ciências da SME-BM e fornecer subsídios para a elaboração de cursos de formação continuada que visem a valorização dos docentes e a melhoria da educação em ciências no município.

Palavras-chave: Ensino de Ciências; Formação Continuada; Professores de Ciências

\begin{abstract}
This article presents the profile of science teachers of basic education of the municipal teaching network of Barra Mansa (SME- BM). To trace this profile, we developed a qualitative study based on data collected in a continuous education in 2017. The objective of
\end{abstract}


this research was to investigate the difficulties and needs of classroom teachers in order to seek possibilities of continuing formation that corresponded to the reality experienced by teachers in school classrooms. The results of the research contribute to broaden the understanding of the challenges of science teachers of SME-BM and provide subsidies for the development of continuing training courses aimed at the exploitation of teachers and the improvement of science education in the municipality.

Keywords: Science Education; Continued education; Science Teachers.

\section{Resumen}

Este artículo presenta el perfil de los profesores de Ciencias de la Enseñanza Fundamental de la Red Municipal de Enseñanza de Barra Mansa (SME-BM). Para trazar ese perfil, se desarrolló un estudio de carácter cualitativo basado en los datos recolectados en una formación continuada en 2017. El objetivo de la investigación fue verificar las dificultades y necesidades de los profesores de aula a fin de buscar posibilidades de formación continuada que correspondiera la realidad vivenciada por los docentes en el aula. Los resultados de la investigación contribuyen a ampliar la comprensión sobre los desafíos de los profesores de ciencias de la SME-BM y proporcionar subsidios para la elaboración de cursos de formación continuada que apunte a la valorización de los docentes y la mejora de la educación en ciencias en el municipio.

Palabras clave: Enseñanza de Ciencias; Formación continua; Profesores de Ciencias

\section{Introdução}

De acordo com o Plano Nacional de Educação do Brasil (PNE) (2011-2020) (BRASIL, 2010), apresenta como desafios a melhoria do ensino e a valorização dos profissionais da educação. De acordo com dados disponíveis no site do Ministério da Educação (MEC) (BRASIL, 2015), 98,2\% das crianças entre 6 e 14 anos de idade estão matriculadas no Ensino Fundamental e a meta é melhorar as taxas de matrículas do Ensino Infantil e do Ensino Médio. É um inegável avanço termos conseguido matricular tantas crianças e jovens na escola. Os resultados dos estudantes brasileiros em avaliações nacionais e internacionais, inclusive as de ciências indicam que, apesar de estarem matriculados no ensino regular, nossos alunos têm graves lacunas em sua formação escolar e que a oferta de um ensino de qualidade ainda representa um obstáculo a ser superado no país, a começar por aspectos relacionados ao professor do ensino básico.É muito importante saber direcionar a formação 
continuada em serviço colocando-a como principal instrumento para a construção de uma sala de aula mais próxima da realidade dos alunos.

Segundo Costa (2011), nas últimas décadas, assistimos ao processo de globalização, ao estabelecimento de novas relações políticos sociais, à expansão da ciência, da tecnologia e da informação. Esse acelerado desenvolvimento da sociedade gerou grandes avanços e provocou o redimensionamento do papel da escola e, consequentemente, do professor.

Com essas mudanças no mundo, o ensino de Ciências ocupa posição de destaque, pois tem muitas aplicações no mundo do trabalho. Para Soares (2012), diante da necessidade de rever o processo de ensino e aprendizagem para que o ensino de ciências seja efetivo diante das demandas do mundo contemporâneo, o professor passa a ser elemento importante para a melhoria da qualidade do ensino de ciências, assim, é necessário auxiliar o professor a refletir sobre sua ação pedagógica e necessidade de formação.

Nesse contexto, a formação do cidadão exige uma ênfase cada vez maior no entrelaçamento entre diferentes áreas do conhecimento, com reflexos nas práticas pedagógicas e nas formas de mobilização dos saberes docente. Para Paganotti e Dickman (2015), conhecer o perfil do professor de Ciências é relevante para todos os agentes do ensino-aprendizagem dessa disciplina: para as instituições que devem oferecer um ensino de qualidade a seus alunos; para os alunos que são os beneficiários diretos do processo; e, principalmente, para os professores que poderão identificar suas qualidades e deficiências no que tange ao perfil de um bom professor.

Este trabalho tem como eixo direcionador a importância das reflexões sobre ações desenvolvidas em formações continuadas em serviço para professores de Ciências dos anos Finais do Ensino Fundamental realizadas no Município de Barra Mansa, Estado do Rio de Janeiro, no ano de 2017.

A formação continuada requer estudos sobre a práxis educativa ${ }^{1}$, na medida em que professores precisam de momentos de reflexão da sua prática pedagógica, tendo em vista que é um constante exercício de reflexão; e as relações existentes entre ensino e aprendizagem.

A reflexão crítica sobre a ação pedagógica em sala de aula é uma exigência da relação entre a teoria e a prática, com o risco da teoria se transformar em um momento enfadonho e a prática ativismo. É importante alinhar e discutir saberes que fundamentam a prática-educativa crítica ou progressista, os quais devem fazer parte dos conteúdos obrigatórios da formação docente. É preciso, sobretudo, entender que um dos saberes indispensáveis, que o formando,

\footnotetext{
${ }^{1}$ Práxis em Freire é a articulação entre teoria e prática.
} 
desde a formação inicial deve compreender que como sujeito da produção do ensino, tenha a convicção de que ensinar não é transferir conhecimento mas criar possibilidades para a construção coletiva. (FREIRE, 1996.p.22)

Pensando nessa reflexão crítica sobre a práxis docente, dividimos esse trabalho em estudos teóricos sobre a importância dos momentos de reflexões das ações docentes em sala de aula nos encontros da rede municipal de ensino e apresentaremos as ações desenvolvidas, concluindo com os resultados das ações realizadas.

Refletir sobre a formação continuada para professores dos anos finais do ensino fundamental é uma questão que guia esse trabalho, na medida que a formação docente deve ser contínua favorecendo as trocas de experiências em sala de aula. No município de Barra Mansa, há uma grande dificuldade em organizar momentos de formação para essa etapa de ensino, seja, por dificuldades de organização do espaço, tempo para formação e a dinâmica escolar de organização para a saída desse professor da escola. Entretanto, houve avanços significativos nas formações continuadas no município desde 2017, no que diz respeito a organização de toda a rede municipal de ensino para que mais encontros de formação continuada acontecesse.

Cabe ressaltar que a formação continuada para os docentes é uma diretriz prevista na Lei 9394/1996, onde no artigo 62, encontramos fundamentos importantes sobre a formação dos profissionais da educação a fim de atender às especificidades do exercício de suas atividades, bem como aos objetivos das diferentes etapas e modalidades da educação básica, tendo em vista: a formação básica que favoreça conhecimentos científicos e sociais das competências de trabalho docente; a unidade entre teoria e prática, capacitação em serviço, entre outros(BRASIL, 1996).

Além disso, a ação da prática exige entre outros fatores a "disponibilidade para o diálogo, pois, como ensinar, como formar sem estar aberto a realidade geográfica, social do educando?” (FREIRE,1996.pg 137) é preciso estar próximo no aconchego da observação e ação para a mediação do ensino.

Fomentar a reflexão docente para que as ações sobre o Ensino de Ciências não se limitem na transmissão de notícias aos alunos sobre as produções científicas sem nenhum significado a sua vida mas que venha cumprir a função social de educar entendendo a Ciência como atividade humana e algo importante que precisa estar em pauta nas discussões.

Investir na reflexão docente, significa trabalhar a Ciência como uma forma de planejar e coordenar pensamento e ação diante do desconhecido, desenvolvendo capacidades investigativas para respostas testáveis (BIZZO, 2009.p.15). É importante oferecer momentos 
de discussões, estudos e aprendizagens, bem como reflexões e sugestões de diversidades metodológicas durante as formações para os docentes visto que as estratégias diversas para o ensino de Ciências poderão ser aplicadas na escola a partir de conexões que favorecerão a construção do conhecimento.

Necessita-se provocar no educando a curiosidade com o docente exercendo o papel de mediador, a fim de que produza significado a relação entre o aluno e o conteúdo que ensina. $\mathrm{Na}$ verdade o papel do educador ao ensinar o conteúdo, não é apenas para que o aluno fixe mas ao falar com clareza sobre o objeto a ser estudado, incitar o aluno a fim de que produza a compreensão do objeto com os materiais que oferece (FREIRE, 1996).

Segundo Amaral e Fracalanza (2008) a formação continuada envolve três processos de desenvolvimento que embasam a carreira docente: o aspecto pessoal, o profissional e o social. No desenvolvimento pessoal deve-se levar em conta a valorização dos conteúdos formativos, a criticidade sobre as ações pedagógicas, utilizando-se dos aspectos teóricos para indicação e resolução de problemas. No aspecto profissional, as articulações de vários saberes devem ser levadas em conta, os oriundos das ações reflexivas, militâncias e conteúdo específicos além das buscas por valorização docente e melhores condições de trabalho digno. No aspecto de desenvolvimento social busca-se para além do trabalho a formação permanente para o exercício da cidadania. (AMARAL e FRACALANZA, 2008)

Sendo assim, pensar na formação docente significa pensar num entrelaçamento entre formação e cotidiano escolar e as diversas concepções de ensino, ciência, educação e sociedade que proporcionarão subsídios necessários para a prática pedagógica efetiva.

Tendo em vista o papel central do professor no processo de mediação para a construção de uma educação em ciências de melhor qualidade, este trabalho traz os resultados de um estudo que teve por objetivo traçar as principais dificuldades e necessidades dos professores de ciências do Ensino Fundamental da Rede Municipal de Ensino de Barra Mansa (SMEBM). Quais as dificuldades e desafios encontrados por esse professor? Quais as possibilidades em sala de aula? Quais são algumas das características relevantes de seu trabalho? Essas foram algumas das questões norteadoras desse estudo que buscou conhecer quem são os docentes da rede municipal de ensino de Barra Mansa do ponto de vista de sua vivência em sala de aula. Para fazer o levantamento do perfil desse professor de ciências, foi desenvolvido um estudo de caráter qualitativo com base em um questionário durante uma reunião para o início da formação continuada com os docentes. Com base na análise aqui apresentada, pretendemos aprofundar a compreensão sobre o perfil do professor de Ciências da Rede 
Municipal de Barra Mansa e contribuir para ampliar o debate referente à profissão docente tanto no nível municipal quanto no nível nacional.

\section{Material e Métodos}

A pesquisa foi do tipo participativa descritiva, com cunho qualitativo. Participamos das ações como mediadores do ensino na formação continuada em determinados momentos discutimos com os educadores, em outros momentos levando-os a reflexão sobre a práxis docente e seus benefícios para o ensino de Ciências. Foi realizado um questionário semiestruturado com perguntas a serem respondidas pelos participantes.

De acordo com Gil (2002) a pesquisa participativa caracteriza-se por seu viés social e envolvimento ativo do pesquisador durante a pesquisa, entende-se a realidade numa postura dialética onde pesquisador e pesquisado identificam-se como sujeitos sociais.

Caracterizamos a pesquisa como descritiva, pois tratamos de aspectos onde descrevemos as características do grupo de docentes, bem como as relações que envolvem o processo de ensino e aprendizagem. Ibidem (2002), caracteriza a pesquisa descritiva tratando de assuntos sobre distribuição por idade, sexo, escolaridade, estado de saúde física e mental, entre outros. Na pesquisa descritiva são incluídas as opiniões, atitudes e crenças de um determinado grupo, como de professores, nosso alvo de pesquisa, onde os saberes docentes foram valorizados a partir das falas e respostas dos professores durante os dois encontros.

É fundamental conhecer melhor o assunto que será desenvolvido nas aulas, como o conhecimento foi produzido, como elaborado e ou pensado por outras pessoas favorecendo o estudo em coletividade em pequenos grupos de estudos, reuniões, trocas de experiências e observações em aulas são momentos oportunos do desenvolvimento profissional do docente (BIZZO, 2009).

Estudamos alguns autores como Paulo Freire e Maurice Tardif os quais tratam de assuntos referentes a formação docente e as relações entre professor e aluno como sujeitos do conhecimento, Chassot e Nélio Bizzo nos serviram de arcabouço sobre o Ensino de Ciências nesta etapa escolar, pois o ensino de Ciências pode contribuir para aquisição de novas experiências pelos alunos e a construção de conceitos científicos que devem acontecer por meio de debates e discussões coletivas (BIZZO, 2009).

Nossa primeira reunião, dia 23 de maio de 2017, os professores participaram do primeiro encontro de formação continuada para o Ensino de Ciências nos Anos Finais do Ensino Fundamental. 
Nessa primeira formação, tivemos um público de 26 professores sendo que 15 participaram no turno da manhã e 11 no turno da tarde. O objetivo dessa primeira reunião foi de apresentar o articulador de área de Ciências Naturais ${ }^{2}$ dos anos Finais do Ensino Fundamental ( $6^{\circ}$ ao $9^{\circ}$ ano) para os professores, iniciando assim, um diálogo para garantia da melhoria e qualidade do ensino na Rede Municipal de Barra Mansa. Foi apresentada as atribuições dos articuladores de área que são de: conhecer os professores da Rede Municipal, suas dificuldades e necessidades profissionais; desenvolver um plano de ação visando a superação das dificuldades diagnosticadas; cooperar com o trabalho dos professores estabelecendo uma relação de parceria profissional e confiança; visitar as escolas; estabelecer contato com os professores de outras disciplinas; participar, com o professor da elaboração do programa bimestral; promover encontros de professores da rede, por área; promover parcerias para a Formação Continuada; possibilitar encontros para a explicitação e valorização das experiências didáticas.

Foi dado um questionário para que os professores respondessem questões referentes ao tempo na docência. Vinte e seis educadores participaram desse primeiro encontro e responderam as seguintes questões:

1) Quanto tempo atua como professor de Ciências?

2) Quais são os principais fatores que limitam o seu trabalho em sala de aula?

3) Quais são as principais dificuldades encontradas no processo de ensino/aprendizagem em Ciências?

No decorrer do desenvolvimento da atividade experimental, o pesquisador foi responsável pela coleta, organização e análise dos dados. Para isso, adotou a observação e anotações em diário de bordo da fala dos professores e gravação de áudio. Os registros das falas das crianças foi o principal instrumento de dados para os resultados. Todas as etapas desse trabalho foram aprovadas pelos professores, que aceitaram participar do processo. Para a exposição dos resultados objetivando a identificação nos registros de participação e criar um ambiente favorável à diversidade de opinião, os professores ao início da atividade, foram identificados com códigos de P1 a P26.

\section{Resultados e Discussão}

_Em relação ao primeiro questionamento que se referia sobre o tempo de docência, temos os seguintes dados:

1- Um Professor com um ano no magistério

\footnotetext{
${ }^{2}$ Professor Orientador que auxilia os docentes nas formações continuadas em serviço.
} 
Res., Soc. Dev. 2019; 8(3):e4583838

ISSN 2525-3409 | DOI: http://dx.doi.org/10.33448/rsd-v8i3.838

2- $\quad$ Um Professor com dois anos no magistério

3- Três Professores com três anos no magistério

4- Um professor com quatros ano no magistério

5- Um professor com cinco anos no magistério

6- Três professores com seis anos no magistério

7- Um professor com sete anos no magistério

8- Dois professores com oito anos no magistério

9- Dois professores com dez anos no magistério

10- Um professor com 11 anos no magistério

11- Um professor com 12 anos no magistério

12- Um professor com 13 anos no magistério

13- Dois professores com 15 anos no magistério

14- Um professor com 16 anos no magistério

15- Dois professores com 17 anos no magistério

16- Um professor com 21 anos no magistério

17- Um professor com 28 anos no magistério

18- Um professor com 30 anos no magistério

Observamos, a partir das respostas docentes, que os anos no magistério variam muito, mas a quantidade de tempo, não representa necessariamente, uma formação sólida e dinâmica e sim as concepções de ensino aprendizagem que os professores vão construindo no decorrer do tempo, por isso, investir na formação continuada desses professores é fundamental para mediar o conhecimento capacitando as futuras gerações, oferecendo criticidade sobre os fatos do cotidiano que envolvem a Ciência.

Percebemos que é preciso levar em conta coisas simples e tão fundamentais, como o tempo de trabalho no magistério, número de alunos, o conteúdo a ser trabalhado, os recursos, as dificuldades encontradas no ofício educativo, as relações entre os docentes, coordenadores e Direção escolar, visto ser onde se processa o trabalho que é realizado por diversas categorias de pessoas (TARDIF, 2002).

Sobre o tempo de docência, importante ressaltarmos que:

Se uma pessoa ensina durante trinta anos, ela não faz simplesmente alguma coisa, ela faz também alguma coisa de si mesma: sua identidade carrega as marcas de sua própria atividade, e uma boa parte de sua existência é caracterizada por sua atuação profissional. Em suma, com o passar do tempo, ela tornou-se - aos seus próprios 
olhos e aos olhos dos outros - um professor, com sua cultura, seu éthos, suas idéias, suas funções, seus interesses etc(TARDIF, RAYMOND.2000.p.02)

Tardif e Raymond nos auxiliam no pensamento de que ao lecionar durante anos, o professor adquire culturas próprias ao seu ofício as quais formarão a identidade docente e fornecerão ferramentas para atuar levando em conta as concepções de ensino que foram sendo construídas no decorrer do ofício docente.

Sobre o segundo questionamento, sobre a aflição dos professores em sala de aula, 21 relatam que a falta de recursos didáticos e estruturais dificultam o ensino, 11 professores abordaram a falta de comprometimento familiar com agravante para o fracasso escolar, 2 professores relatam a dificuldade no trabalho com os alunos de inclusão com fator que aflige a prática docente, 8 professores relataram o desinteresse com fator que aflige a prática docente, 4 abordaram a questão da indisciplina como causa que aflige a prática docente.

De forma mais pontual, surgiram relatos com dificuldades relacionadas a falta de livro didático para algumas turmas, falta de diário de classe no início do ano letivo, falta de Orientador Educacional e Pedagógico na Unidade Escolar e o apoio Pedagógico e Educacional, salas lotadas, falta de estudos entre professores de outras áreas, falta de prérequisitos básicos ( leituras, cálculos, entre outros) a falta de respeito, falta de capacitação em serviço, falta de Kit para atividades práticas, Dois abordaram a questão da distorção idade série como causa que aflige a prática pedagógica.

Ao lermos as respostas dos professores, percebemos como as falas são referentes as dificuldades encontradas na estrutura física escolar, falta de recursos didáticos, laboratórios, questão da indisciplina, entre outros. No entanto a reflexão na ação no que diz respeito ao processo didático de ensino, nas relações cotidianas com a proposta metodológico e as diversas possibilidades de aprendizagens não foram ressaltadas pelos professores.

Pensar no aluno como sujeito do conhecimento também é uma função urgente, embora, existem muitas literaturas e discussões sobre o processo de ensino e aprendizagem, percebemos nos discursos docentes que ainda é muito difícil quebrar paradigmas de concepções e visões de mundos ultrapassados, pois “... a prática docente do pensar certo envolve o movimento dinâmico, dialético entre o fazer e o pensar (FREIRE, 1996.p.38).

No que diz respeito as dificuldades encontradas na disciplina, no processo ensinoaprendizagem, os educadores relataram que os seguintes aspectos comprometem a efetivação do processo do ensino e aprendizagem: 
Professores falaram sobre a incapacidade de leitura e interpretação textual( imagens, gráficos, tabelas) para resolução de exercícios e provas, dificuldade em mostrar para o aluno certos conteúdos que necessitam de espaço adequado, falta de comprometimento, alunos desmotivados, alunos com transtornos, sem acompanhamento clínico, falta de material tecnológico, dificuldades na compreensão de processos, falta de unidade entre a prática com conteúdo e a utilização de recursos para a experimentação, Falta de laboratório de Ciências e demais recursos( maioria), Falta de apoio no que se refere ao rigor do ensino e das avaliações, Defasagem de conteúdos na disciplina e em Português e Matemática, Alunos com baixa estima e desmotivado, Falta de equipamentos e locais adequados para aulas atrativas, Falta de recursos tecnológicos e perspectiva dos alunos.

Vários professores abordaram questões sobre a falta de pré-requisitos dos anos iniciais, falta formação continuada, Currículo extenso, falta de tempo de estudo e dedicação por parte dos alunos, falta de recursos financeiros para a efetivação das aulas- passeio, Indisciplina em sala de aula, direção indisponível para diálogos e projetos, Recomendação- apropriação do uso do celular na escola. Antigamente, a calculadora era proibida, agora é uma aliada na educação, democratização do Museu Interativo para os alunos do CIEP 054, tempo insuficiente para as turmas do $9^{\circ}$ ano nas disciplinas de química e física, livros insuficientes, dificuldades na disciplina, falta de compromisso e pontualidade. Nessa parte do questionário, notou-se que a maioria dos professores relataram todos os aspectos mencionados.

Muitas foram as dificuldades levantadas pelos professores, por isso, é preciso repensar as ações e relações que envolvem professor e aluno pois o nível dos alunos em conhecimentos científicos está abaixo da média e o investimento brasileiro em educação é insuficiente, mas não podemos deixar de insistir contribuindo para que os alunos dominem a leitura e escrita com autonomia, aprendam conceitos básicos das ciências naturais aplicando os princípios apreendidos ao cotidiano, favorecendo a compreensão que se relacionam entre ciência, sociedade e tecnologia(FRACALANZA, 1986,p.26-27)

Apesar das inúmeras dificuldades salientadas pelos educadores durante o primeiro momento da formação, algumas experiências de sucesso foram coletadas e apresentadas num segundo momento de interação coletiva, demonstrando o quanto o trabalho dos professores pode ser considerado como um espaço de produção, transformação e mobilização de saberes práticos em interação com aspectos teóricos oriundos dos conhecimentos e saberes específicos do ofício docente (TARDIF, 2002)

Investir na reflexão durante as ações docentes, significa trabalhar a Ciência como uma postura individual e coletiva, numa maneira de planejar e coordenar pensamento e ação diante 
do desconhecido, desenvolvendo capacidades investigativas para inúmeras respostas que podem testáveis (BIZZO, 2009).

Um Professor de uma Escola Municipal no ano de 2017, numa turma de $8^{\circ}$ ano, realizou um projeto com o eixo temático Ciência e Arte intitulado "Aborto: Reflexões e práticas na Adolescência" onde ações foram desenvolvidas com os alunos, tendo em vista a reflexão sobre questões do aborto durante a adolescência, visto que a educação que se propões libertadora fundamenta-se em seres humanos conscientes de suas relações com o cotidiano que os cerca, logo, refletir sobre a gravidez na adolescência e reconhecer a temática do aborto como um problema de saúde, faz parte da realidade de muitos adolescentes que vivenciando essa fase de mudanças físicas, emocionais, mentais e sociais precisam de apoio e reflexão sobre a gravidez e aborto na adolescência.

De acordo com relatos do professor, durante a realização do projeto os alunos realizaram um teatro com roteiro produzido por eles mesmos e gravaram um vídeo dentro da sala de aula onde os assuntos sobre a gravidez e aborto foram encenados pelos discentes, os quais demonstraram motivação e envolvimento durante as ações de aprendizagens sobre os conteúdos trabalhados.

Ações como essas, demonstram o quanto é importante refletir e pensar em práticas dinâmicas que envolvem o ensino de conceitos que retratam o real, num universo de encenação que dialogam com o cotidiano propondo problematizações sobre as escolhas e consequências da vida. Articular Ciência e Arte num movimento de práticas escolares é um caminho para trabalhar temas tão polêmicos e recorrentes na realidade de muitos.

A educação como problematizadora implica em compreendermos o homem, não como um indivíduo solto, isolado do mundo, desligado de sua realidade, mas, de um sujeito imerso em suas relações com o mundo real, onde a consciência e mundo se relacionam simultaneamente (FREIRE, 1996).

Pensar para além do óbvio, tendo em vista os estereótipos e paradigmas produzidos socialmente referentes aos meninos e meninas, em especial, na adolescência, também é algo que o ensino de ciência em interação com outras áreas do saber, como a arte teatral foi um exemplo teórico/prático em que muitos conhecimentos foram construídos, compartilhados numa atividade bem sucedida.

A professa de uma determinada escola realizou uma atividade com as turmas do $6^{\circ}, 7^{\circ} \mathrm{e}$ $8^{\circ}$ anos tendo o objetivo de desenvolver o gosto pela ciência, buscando a interação entre turmas e professores por meio de jogos científicos que foram realizados entre as turmas, 
oportunizando interações e aprendizagens coletivas, visto ser o jogo um recurso importante para auxiliar o ensino.

Uma educadora relatou uma atividade denominada "Cienciando Por Aí", onde a professora compartilhou com os alunos, pais e responsáveis, amigos, entre outros, familiares os trabalhos, vídeos e nossas atividades divertidas realizadas em sala de aula, com campeonato de curtidas nos trabalhos, álbum compartilhado de fotos postadas pelos próprios alunos. A professora relatou, também, que, realiza postagens de campanha sobre meio ambiente auxiliando na informação e divulgação da Ciência além de favorecer o envolvimento entre a comunidade escolar e local.

Uma das professoras participantes desenvolveu uma atividade com o $8^{\circ}$ ano cujo eixo temático foi “ Saúde” com o título de Alimentação Saudável tendo como objetivo geral desenvolver hábitos alimentares saudáveis a partir de uma boa alimentação, identificando os alimentos fundamentais para o cardápio diário, bem como o aprendizado e escolha alimentos saudáveis e de boa qualidade, levando em conta as condições sociais.

No primeiro momento os alunos formaram grupos e escolheram um tema relacionado com a alimentação saudável, depois, um segundo momento eles montaram uma apresentação onde demonstraram aos colegas o tema escolhido, num terceiro momento, uma nutricionista foi convidada até a unidade escolar onde ministrou uma palestra sobre a importância da Alimentação Saudável e os benefícios sobre a alimentação.

Um professor, numa turma de $8^{\circ}$ ano desenvolveu uma atividade com o objetivo de promover ensino significativo a partir de um sifão de pia, garantindo compreensão das funções intestinais de forma de dinâmica e interativa demonstrando a ação da bile sobre as gorduras. O professor gravou um pequeno vídeo e depois apresentou aos alunos, demosntrando os conteúdos referentes a digestão através dos vídeos, interação e atividades de ensino envolvendo as redes sociais.

De acordo com o professor que realizou a atividade, o uso de um sifão de pia como recurso de ensino de Ciências pode ajudar no ensino e entendimento de como as comodidades intestinais ampliam a área de absorção do intestino.

Duas professoras do $6^{\mathrm{a}}$ e $7^{\mathrm{a}}$ anos relataram a atividade desenvolvida com seus alunos a partir de desenhos representativos da estrutura da Terra, em que os alunos foram levados a transpor os conhecimentos apreendidos em aula por meio de representações com o uso de imagens.

\section{Considerações finais}


Os estudos relacionados ao perfil do professor de Ciências são necessários para enfatizar alguns aspectos do trabalho docente em sala de aula, a fim de problematizá-los e analisá-los tendo em vista as frequentes mudanças dos adolescentes nos dias atuais. Os resultados obtidos indicam que a partir do perfil dos professores em exercício, podem obter-se subsídios para discutir as necessidades de formação continuada dos professores de Ciências diante dos complexos desafios educacionais. No entanto, é preciso oferecer ao professor a oportunidade de, constantemente, exercitar, ampliar e renovar sua cultura, para que este possa trabalhar situações concretas por mais modestas que sejam as condições em que o aluno sinta o prazer de conquistar o conhecimento.

Refletir sobre a formação continuada dos professores dos anos finais do Ensino Fundamental foi uma tarefa que guiou nosso breve estudo, onde procuramos entender, a partir de ações realizadas em momentos de formação em serviço, os dilemas e as possibilidades encontradas na práxis docente cotidiana.

Percebemos que, embora as vozes docentes retratavam aspectos referentes à indisciplina, desinteresse, falta de pré-requisitos básicos de leitura, escrita e cálculo, alguns docentes demonstraram, a partir de ações articuladas entre teoria e prática que existem formas diversas de diversificar o ensino com atividades capazes de promover o ensino mais dinâmico.

Foi notório, nesses encontros, o quanto a coletividade é fundamental para o crescimento profissional e humano por meio das dificuldades levantadas, podemos pensar em maneiras e técnicas para melhorar o ensino, ao mesmo tempo em que podemos apropriar das experiências que nossos pares realizaram as quais deram certo e assim começar a superar o isolamento do professor em sala de aula.

Dentro desta perspectiva, partilhamos o pensamento de educadores que defendem a importância e a necessidade da melhoria formação continuada em serviço através do diálogo com o professor pela sua vivência em sala de aula pois só assim haverá mudanças na qualidade de ensino. Este estudo carrega consigo uma abordagem inicial sobre a formação e prática docente dos professores de Ciências do $6^{\circ}$ ao $9^{\circ}$ ano do Ensino Fundamental na rede municipal de Barra Mansa - RJ, sendo necessários estudos posteriores que reforcem as afirmações aqui contidas.

\section{Referências}


BRASIL. Ministério da Educação Projeto de lei. Aprova o Plano Nacional de Educação 20112020 e dá outras providências. Brasília: MEC, 2010. Disponível em: . Acesso em: 24 out. 2017.

BRASIL. Ministério da Educação Relatório educação para todos: versão preliminar. Brasília: MEC, 2015.

AMARAL. I. A. do. FRACALANZA, H. Formação Continuada no Ensino de Ciências: Programas e ações. Revista Ciências em Foco, v.01, n.01, 2008.

BIZZO, N. Ciências, Fácil ou difícil?/ Nélio Bizzo 1ª ed.-São Paulo: Bituta, 2009.

BIZZO, N. Mais Ciências no Ensino Fundamental: metodologia de ensino em foco. São Paulo: Editora do Brasil, 2009.

BRASIL. Lei de Diretrizes e Bases da Educação Nacional de 20 de dezembro de 1996.

COSTA, F.R.A. Um estudo sobre o perfil dos professores de matemática da rede municipal de Contagem - MG. 52p. Especialização em Matemática do Instituto de Ciências Exatas da Universidade Federal de Minas Gerais. 2011

FRACALANZA, H. O ensino de ciências no primeiro grau. São Paulo: Atual. 1986.

FREIRE, P.- Pedagogia da autonomia: saberes necessários à prática educativa/Paulo Freire.- São Paulo: Paz e Terra, 1996.

GIL, A. C. Como elaborar projetos de pesquisa. São Paulo: Atlas, 2002.

PAGANOTTI.A.; DICKMAN.G.A. Caracterizando o professor de Ciências: Quem ensina tópicos de Física no ensino fundamental ? Disponível em:

<http://www.nutes.ufrj.br/abrapec/viiienpec/resumos/R0793-2.pdf> Acesso em: 02/10/2017

SOARES, V.R. O Ensino de Física no $9^{\circ}$ ano de escolaridade - Um estudo sob a

Perspectiva dos professores de Ciências de uma Escola Municipal de Duque de Caxias. 68 p. Dissertação de conclusão do Mestrado Profissional em Ensino de Ciências. Programa de Pós

Graduação Stricto Sensu em Ensino de Ciências, Instituto Federal de Educação, Ciência e Tecnologia do Rio de Janeiro (IFRJ), Campus Nilópolis, Nilópolis, RJ, 2012

TARDIF, M. RAYMOUND, D. Saberes, tempo e aprendizagem do trabalho no magistério. Rev. Educ. Soc., v.21, n.239 o 73, 2000.

TARDIF, M. Saberes docentes e formação profissional. Rio de Janeiro: Vozes, 2002. 